\title{
Effect of Maleated Polyethylene on the Crystallization Behavior of LLDPE/Clay Nanocomposites
}

\author{
Youn Cheol $\mathrm{KIM}^{\dagger}$ \\ Division of Advanced Materials Engineering, Kongju National University, \\ 175, Budae-Dong, Cheonan, Chungnam 330-717, Korea
}

(Received June 29, 2005; Accepted October 26, 2005; Published March 15, 2006)

\begin{abstract}
The crystallization behavior and microstructure of linear low density polyethylene (LLDPE)/modified montmorillonite (20A) composites containing maleic anhydride grafted polyethylene (MA-g-PE) were investigated by differential scanning calorimetry (DSC), X-ray diffraction (XRD), and transmission electron microscope (TEM). The dispersion of 20A in LLDPE matrix depended on the amount of MA-g-PE. The degree of super cooling reduced when 20A was introduced into LLDPE with MA-g-PE. The Avrami analysis shows that the nonisothermal crystallization process of the LLDPE/20A composites followed the Avrami equation with Avrami exponent value in the range of 2.75-3.97. The activation energies calculated by Kissinger method were $986 \mathrm{~kJ} / \mathrm{mol}$ for LLDPE, $949 \mathrm{~kJ} / \mathrm{mol}$ for PEA5MA0, $1445 \mathrm{~kJ} / \mathrm{mol}$ for PE-A5MA5, and $1581 \mathrm{~kJ} / \mathrm{mol}$ for PE-A5MA20. The activity of nucleation of PE-A5MA0 was 0.75 but the values of the composites with MA-g-PE were in the range of $0.37-0.56$. These behaviors can be interpreted by the fact that the loading of MA-g-PE in LLDPE/20A composites enhances the dispersion of clay in LLDPE matrix and the good dispersion of 20A affects the degree of super cooling and the nucleation activity of silicate. [DOI 10.1295/polymj.38.250]

KEY WORDS Maleic Anhydride / Linear Low Density Polyethylene / Nanocomposite / Crystallization Behavior / Nucleation Activity /
\end{abstract}

Polymer nanocomposites comprise a new class of materials where the particulates are finely dispersed within a matrix. There is much interest, scientifically and technologically, in nanocomposites of polymers with nanoscale layered silicates because these materials offer markedly improved properties as compared to the conventional polymer composites. ${ }^{1-8}$ Further, these improvements are achieved at very low loadings of the inorganic component.

In the case of semicrystalline polymers, it is well known that the crystallization behavior get affected by the presence of particulate additives especially at low concentrations. This feature can affect the overall properties of the nanocomposite but such a few investigations have been reported. ${ }^{9,10}$ Nonisothermal crystallization studies on semicrystalline polymers have been widely carried out because of the analogous crystallization condition to that of real processing. Although the analysis for the nonisothermal crystallization process may much more complicated than that for isothermal process, nonisothermal crystallization measurements can provide ample information about the crystalline transition. Since the microstructures of silicate and the linear low density polyethylene (LLDPE) matrix crystallite may have remarkable effects on the physical properties of the LLDPE/silicate nanocomposites, it is meaningful to study the influence of silicate on the crystallization process of
LLDPE matrix. This is the reason that the study of the LLDPE/silicate nanocomosite on the crystallization behavior is a topic of interest.

Another field of interest with the polymer nanocomposite was that the outstanding properties of the nanocomposites derive from the unique phase morphology and improved interfacial properties. ${ }^{11-14}$ Since LLDPE does not include any polar group in its backbone, it is thought that the homogeneous dispersion of the clay minerals in polyethylene is not realized. In general, the clay is modified with alkylammonium to facilitate its interaction with a polymer because the alkylammonium make the hydrophilic clay surface organophilic. However, the organically modified clay does not disperse well in the nonpolar polypropylene or polyethylene since such non-polar polymers are still too hydrophobic.

Initial attempts to create the nonpolar polymer/clay nanocomposites by simple melt mixing were based on the introduction of a modified oligomer to mediate the polarity between the clay surface and polymer. ${ }^{15-17}$ One of the typical examples is maleic anhydride grafted polyethylene (MA-g-PE)/clay nanocomposites system. Although there have been considerable studies on the physical properties of the polyolefin nanocomposites, little progress has been made in the effect of MA-g-PE content on the crystallization behavior of LLDPE/clay nanocomposite.

${ }^{\dagger}$ To whom correspondence should be addressed (E-mail: younkim@kongju.ac.kr). 
The present study was carried out to determine the effects of MA-g-PE content on nonisothermal crystallization behavior of LLDPE/clay nanocomposites using Avrami ananlysis, Kissinger, and Dovreva's method. LLDPE/clay nanocomposites containing MA-gPE was accomplished with a laboratory-scale melt mixer and a systematic study was made on the effects of MA-g-PE concentrations.

\section{EXPERIMENTAL}

\section{Materials}

Polyethylene used in this study was LLDPE from Samsung General Chemicals of Korea with a melt in$\operatorname{dex}=2.4 \mathrm{~g} / 10 \mathrm{~min}\left(190^{\circ} \mathrm{C}, 2.16 \mathrm{~kg}\right)$ and a density $=$ $0.923 \mathrm{~g} \cdot \mathrm{cm}^{-3}$.

The modified montmorillonite (Closite 20A, abbreviation: 20A) supplied by Southern Clay Products was used, which was ion-exchanged with dimethyl dihydrogenate tallow ammonium ions. (Tallow was composed pre-dominantly of octadecyl chains with smaller amount of lower homologues. The approximate composition was $\mathrm{C}_{18} 65 \%, \mathrm{C}_{16} 30 \%$ and $\mathrm{C}_{14} 5 \%$.)

Maleic anhydride modified polyethylene (MA-gPE, 0.85 wt \% maleic anhydride grafted, Aldrich) were used. All chemicals were used without further purification.

Several types of the composites with different compositions of the organically modified clays and LLDPE containing MA-g-PE were prepared by melt compounding at $140^{\circ} \mathrm{C}$, using Brabender mixer with the chamber size of $50 \mathrm{~cm}^{3}$. Screw speed was $60 \mathrm{rpm}$ and the mixing time was 20 min for all the cases.

\section{Measurements}

X-Ray diffraction (XRD) was carried out by using Rigaku X-ray generator $(\mathrm{Cu} \mathrm{K} \alpha$ radiation with $\lambda=$ $0.15406 \mathrm{~nm}$ ) at room temperature. The diffractograms were scanned in $2 \theta$ ranges from 1.2 to $50^{\circ}$ at a rate of $4^{\circ} \cdot \mathrm{min}^{-1}$. Transmission electron microscope (TEM), Pillips CM20, was used to observe the dispersibility of the clay in hybrids using an acceleration voltage of $120 \mathrm{kV}$. An ultra-thin section of $70 \mathrm{~nm}$ in thickness was prepared by an ultra-microtome Leica EM FCS. Nonisothermal crystallization was carried out on a differential scanning calorimetry (DSC) of TA Instruments (TA50). Heating rate was fixed at $20^{\circ} \mathrm{C} \cdot \mathrm{min}^{-1}$ and all measurements were run under an atmosphere of dry nitrogen. FT-IR experiments were used to measure the maleic anhydride (MA) grafting level to polyethylene prepared by melt extrusion. The FT-IR spectra were recorded on a Bomen-MB-100 FT-IR spectrometer with a $4 \mathrm{~cm}^{-1}$ resolution. Melt viscosities were measured by using an oscillatory viscometer (Physica, Rheo-Lab MC 120) in a parallel plate type of geometry ( $12.5 \mathrm{~mm}$ in radius) at $200^{\circ} \mathrm{C}$. Disk-shaped samples were molded at $200{ }^{\circ} \mathrm{C}$ by a laboratory hot press under about 10 metric tons and dried in a vacuum oven for $24 \mathrm{~h}$ before the test. The samples were diameter in $25 \mathrm{~mm}$ and thickness was $2 \mathrm{~mm}$. The gap between the plates was $1.2 \mathrm{~mm}$.

\section{RESULTS AND DISCUSSION}

\section{The Basic Properties of LLDPE/Clay Composites}

LLDPE/20A composites were prepared by melt compounding, and the effect of MA-g-PE on the basic properties of the composites was investigated as the previous results. ${ }^{18}$ The formulation and thermal properties of the composites are summarized in Table I. The MA grafting level was measured from the intensity of $1780 \mathrm{~cm}^{-1}$ of IR spectrum and the thickness variation of each sample were corrected by 2019 $\mathrm{cm}^{-1}$ intensity for internal reference peak. ${ }^{19}$ MA weight percentages calculated by peak ratio are also summarized in Table I.

MA-g-PE concentration will be important thing to the 20A dispersion in LLDPE/20A composite. The effects of MA-g-PE on the interlayer spacing of the 20A in LLDPE matrix were investigated. The content of the $20 \mathrm{~A}$ is fixed at $5 \mathrm{wt} \%$ in all composites. XRD patterns of the LLDPE/20A composites with MA-g-PE are shown in Figure 1. The X-ray pattern shows clearly that the interlayer spacing increases with the increase in content of MA-g-PE. The interlayer spacing of 20A, PE-A5MA0, PE-A5MA5, and PE-A5MA15 are $2.29 \mathrm{~nm}, 3.07 \mathrm{~nm}, 3.28 \mathrm{~nm}$, and 3.46 , respectively. However, the original basal reflection peak of $20 \mathrm{~A}$ disappears almost above a certain concentration of MA-g-PE, which is about $15 \mathrm{wt} \%$. This fact reveals that clays are dispersed homogeneously in the LLDPE matrix with MA-g-PE.

Table I. Formulations and basic properties of the LLDPE/20A composites

\begin{tabular}{lccccc}
\hline \multicolumn{1}{c}{ Sample } & $\begin{array}{c}\text { LLDPE/20A/ } \\
\text { MA-g-PE (wt \%) }\end{array}$ & $\begin{array}{c}\text { Grafted }^{\mathrm{a}} \\
\text { MA }(w t \%)\end{array}$ & $\begin{array}{c}T_{\mathrm{m}} \mathrm{b} \\
\left({ }^{\circ} \mathrm{C}\right)\end{array}$ & $\begin{array}{c}\Delta \mathrm{H} \\
(\mathrm{J} / \mathrm{g})\end{array}$ & $\begin{array}{c}T_{\mathrm{d}}{ }^{\mathrm{c}} \\
\left({ }^{\circ} \mathrm{C}\right)\end{array}$ \\
\hline LLDPE & $100 / 0 / 0$ & 0 & 127.1 & 63.5 & 374 \\
PE-A1MA0 & $99 / 1 / 0$ & 0 & 125.9 & 63.4 & 388 \\
PE-A3MA0 & $97 / 3 / 0$ & 0 & 126.0 & 58.1 & 399 \\
PE-A5MA0 & $95 / 5 / 0$ & 0 & 126.9 & 51.5 & 400 \\
PE-A7MA0 & $93 / 7 / 0$ & 0 & 128.2 & 53.4 & 428 \\
PE-A5MA5 & $90 / 5 / 5$ & 0.036 & 128.5 & 62.3 & 441 \\
PE-A5MA10 & $85 / 5 / 10$ & 0.088 & 129.6 & 59.4 & 445 \\
PE-A5MA15 & $80 / 5 / 15$ & 0.123 & 129.5 & 52.0 & 457 \\
PE-A5MA20 & $75 / 5 / 20$ & 0.164 & 127.4 & 64.7 & 370 \\
\hline
\end{tabular}

${ }^{\mathrm{a}}$ Calculated from FT-IR data. ${ }^{\mathrm{b}}$ Melting temperature measured by DSC at $20^{\circ} \mathrm{C} / \mathrm{min}$. ${ }^{\mathrm{c}}$ Degradation temperature measured by TGA at $20^{\circ} \mathrm{C} / \mathrm{min}$. 


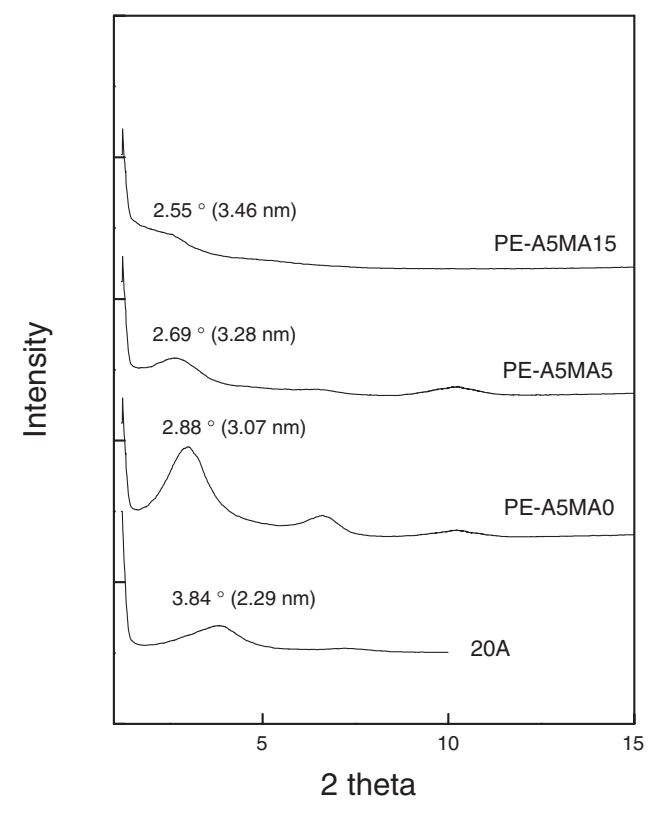

Figure 1. XRD patterns for the LLDPE/20A composites with increase in MA-g-PE.

In order to confirm the nanoscale dispersion of clay, the morphologies of the composites with or without MA-g-PE were observed by transmission electron microscopy (TEM). In Figure 2, the dark lines are the clay layers. In case of PE-A5MA15 with MA-g$\mathrm{PE}$ of $15 \mathrm{wt} \%$, each layer of clay is disordered and dispersed homogeneously in the composite as shown in Figure 2(c). It is consistent with the weakness of (001) plane peak in Figure 1 due to very large interlayer spacing and the disordered state of the clay layer. However, in the hybrid without MA-g-PE, there is a strong peak at a lower angle $\left(2 \theta=2.88^{\circ}\right)$ than the basal reflection peak position of $20 \mathrm{~A}\left(2 \theta=3.84^{\circ}\right)$. This indicates that some parts of $20 \mathrm{~A}$ are intercalated by LLDPE but some parts of 20A are not intercalated. Apparently, a macrophase separation textures were observed in some parts as shown in Figure 2(a). From these results, it is found that the maleated modification is an important factor to improve the dispersion of clay in the LLDPE matrix.

\section{Nonisothermal Crystallization Analysis of LLDPE/ 20A Composites}

Figure 3 shows the exothermic peaks of the LLDPE/20A composites without MA-g-PE during nonisothermal crystallization. The peak temperatures of the curves are summarized in Table II. The exothermic peak temperature shifts to lower value as the cooling rate increases. On the other hand, there was no remarkable change in the exothermic peak temperature of the LLDPE/20A composites as the clay amount increases. That is, an introducing of organic clay in LLDPE matrix was little influenced on

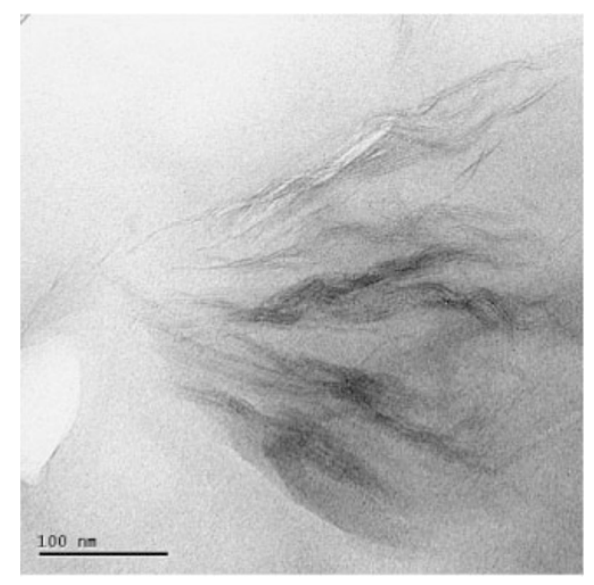

(a)

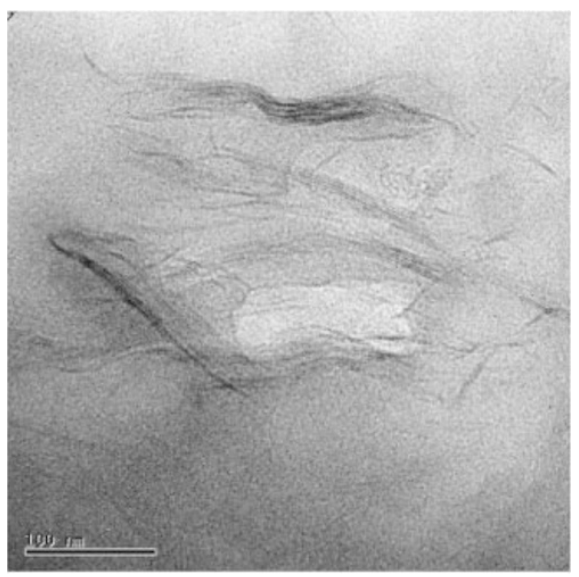

(b)

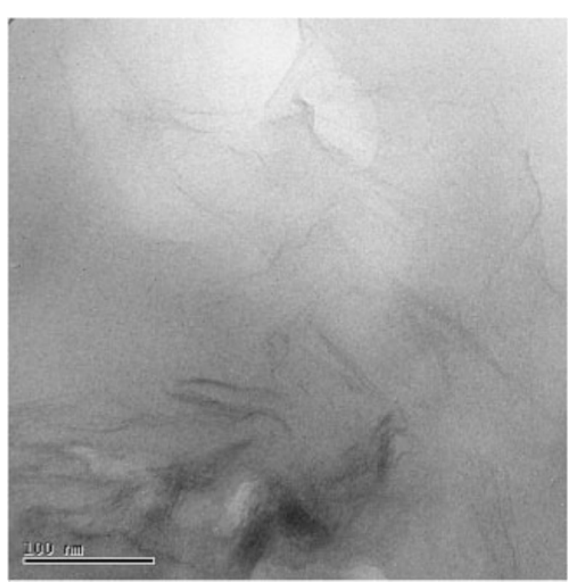

(c)

Figure 2. TEM images for the LLDPE/20A composites: (a) PE-A5MA0, (b) PE-A5MA5, and (c) PE-A5MA15.

super cooling effect of LLDPE matrix.

MA-g-PE concentration will be important thing to the 20A dispersion in LLDPE/20A composite. The effects of MA-g-PE on the exothermic peak of LLDPE/ $20 \mathrm{~A}$ were investigated. The content of the $20 \mathrm{~A}$ is fixed at $5 \mathrm{wt} \%$ in all composites. Heat flow patterns of the LLDPE/20A composites with MA-g-PE are shown in Figure 4. Compared with that for the composite with- 


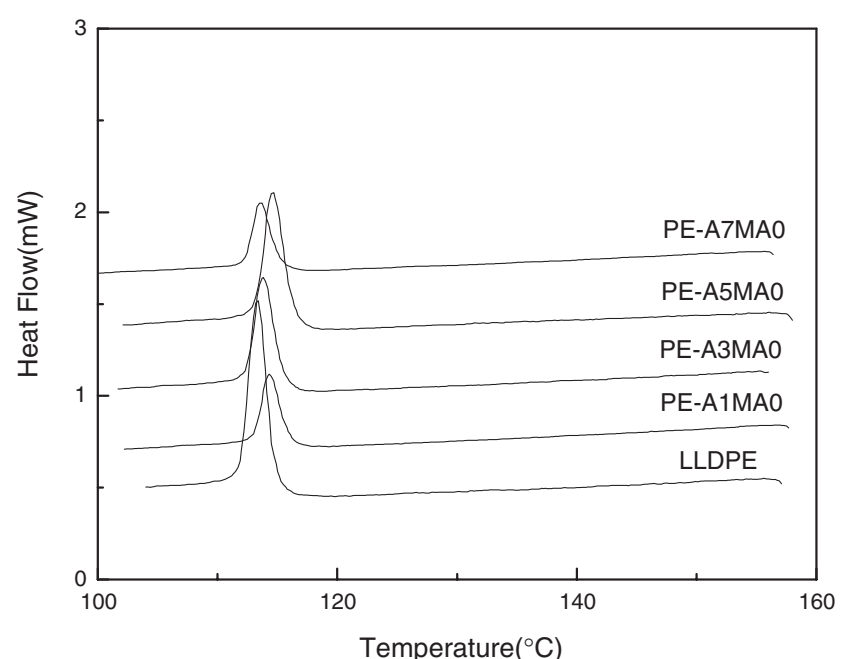

(a)

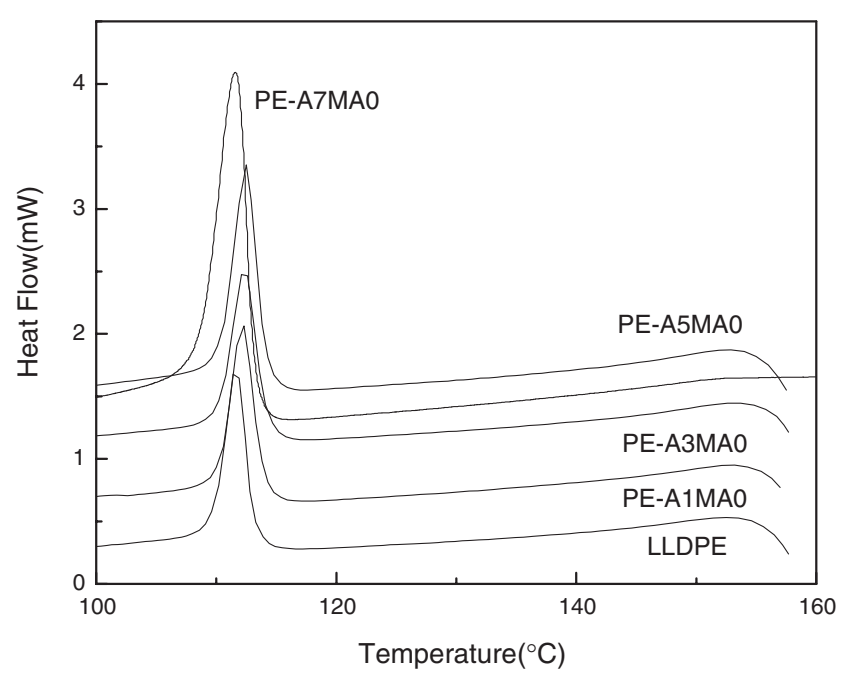

(b)

Figure 3. DSC curve patterns of the LLDPE/20A composites without MA-g-PE: (a) $-1{ }^{\circ} \mathrm{C} / \mathrm{min}$ and (b) $-5^{\circ} \mathrm{C} / \mathrm{min}$.

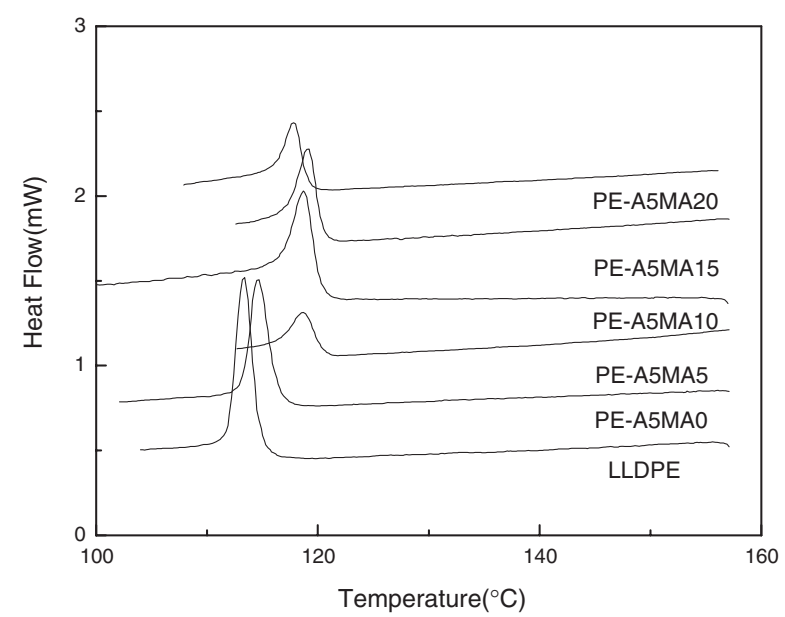

(a)

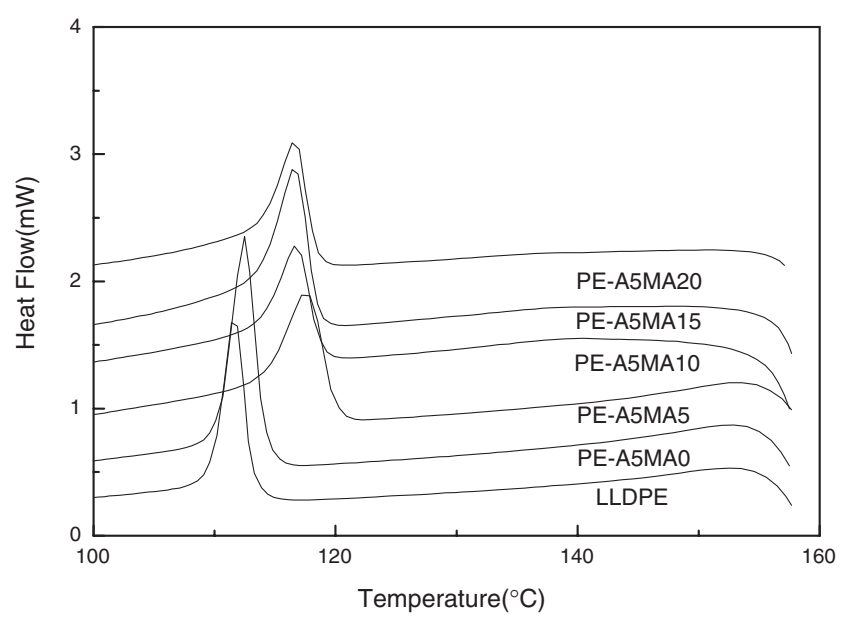

(b)

Figure 4. DSC curve patterns of the LLDPE/20A composites with MA-g-PE: (a) $-1{ }^{\circ} \mathrm{C} / \mathrm{min}$ and (b) $-5^{\circ} \mathrm{C} / \mathrm{min}$.

Table II. The kinetics parameters of LLDPE/20A composites

\begin{tabular}{|c|c|c|c|c|c|c|}
\hline \multirow{2}{*}{ Sample } & \multicolumn{3}{|c|}{$-1^{\circ} \mathrm{C} / \min ^{\mathrm{a}}$} & \multicolumn{3}{|c|}{$-5^{\circ} \mathrm{C} / \mathrm{min}$} \\
\hline & $T_{\mathrm{p}}{ }^{\mathrm{b}}\left({ }^{\circ} \mathrm{C}\right)$ & $n$ & $K\left(\mathrm{~S}^{-n}\right)$ & $T_{\mathrm{p}}^{\mathrm{b}}\left({ }^{\circ} \mathrm{C}\right)$ & $n$ & $K\left(\mathrm{~S}^{-n}\right)$ \\
\hline LLDPE & 113.4 & 3.77 & $9.71 \times 10^{-10}$ & 111.4 & 3.85 & $4.11 \times 10^{-8}$ \\
\hline PE-A1MA0 & 114.3 & 3.96 & $2.47 \times 10^{-10}$ & 112.3 & 3.68 & $1.49 \times 10^{-7}$ \\
\hline PE-A3MA0 & 113.8 & 3.91 & $3.73 \times 10^{-10}$ & 112.1 & 3.75 & $6.10 \times 10^{-8}$ \\
\hline PE-A5MA0 & 114.7 & 3.70 & $1.45 \times 10^{-9}$ & 112.5 & 3.42 & $2.11 \times 10^{-6}$ \\
\hline PE-A7MA0 & 113.7 & 3.97 & $1.34 \times 10^{-10}$ & 111.6 & 3.39 & $5.62 \times 10^{-7}$ \\
\hline PE-A5MA5 & 118.7 & 3.20 & $1.53 \times 10^{-8}$ & 117.2 & 3.30 & $1.83 \times 10^{-7}$ \\
\hline PE-A5MA10 & 118.7 & 3.79 & $2.19 \times 10^{-10}$ & 116.6 & 2.89 & $1.94 \times 10^{-6}$ \\
\hline PE-A5MA15 & 119.2 & 3.71 & $1.87 \times 10^{-9}$ & 116.4 & 2.77 & $2.44 \times 10^{-6}$ \\
\hline PE-A5MA20 & 117.8 & 2.98 & $1.06 \times 10^{-7}$ & 116.4 & 2.75 & $4.08 \times 10^{-6}$ \\
\hline
\end{tabular}

${ }^{\mathrm{a}}$ Cooling rate. ${ }^{\mathrm{b}}$ Peak temperature in cooling scan.

out MA-g-PE, the exothermic peaks for the composites with MA-g-PE distinctly shift to higher temperatures as shown in Table II. This indicates that the degree of super cooling reduces when 20A was introduced into LLDPE with MA-g-PE. The decrease in super cooling effect can be interpreted by the fact that the loading of MA-g-PE in LLDPE/20A composites enhances the dispersion of clay in LLDPE matrix. Enhancement of the dispersion of clay was certified by TEM morphology as shown in Figure 2. 


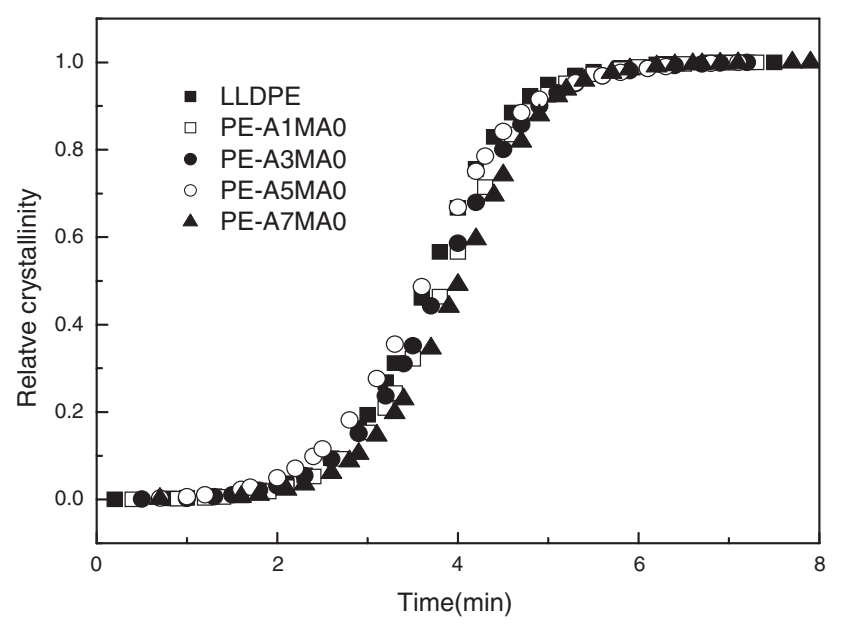

(a)

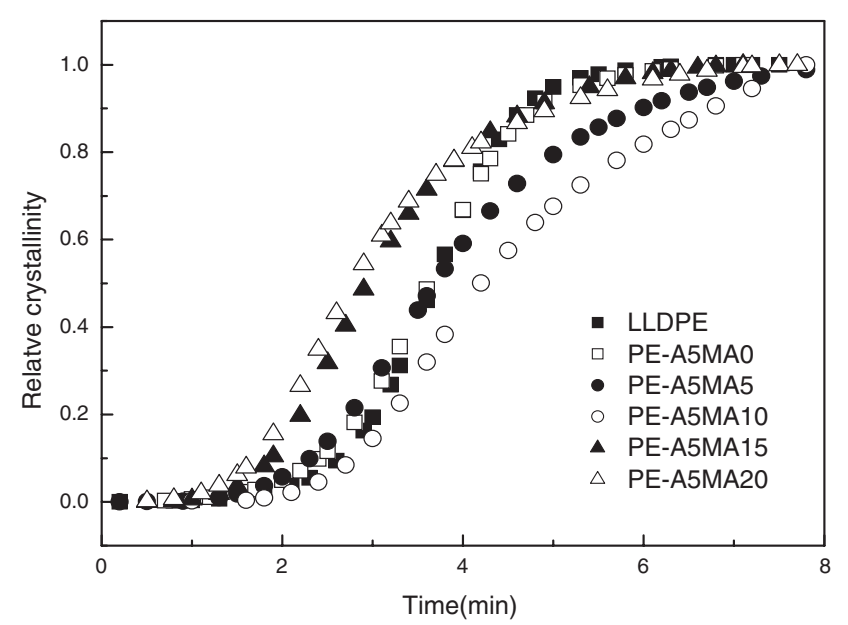

(b)

Figure 5. Relative crystallinity of the LLDPE/20A composites before (a) and after (b) loading MA-g-PE with the crystallization time.

In order to analyze the crystallization process, the nonisothermal crystallization analysis was made for the LLDPE/20A composites. Several methods have been developed to describe the nonisothermal crystallization kinetics of polymers. The nonisothermal crystallization behavior can be analyzed by the Avrami equation: ${ }^{9,20}$

$$
X(t)=1-\exp \left(-K t^{n}\right)
$$

or

$$
\log [-\ln (1-X(t))]=n \log t+\log K
$$

where $X(t)$ is relative crystallinity at crystallization time $t, n$ is the Avrami exponent, $K$ is the crystallization rate constant. In the nonisothermal crystallization process, the crystallization time $t$ can be determined as follows:

$$
t=\frac{T_{0}-T}{\phi}
$$

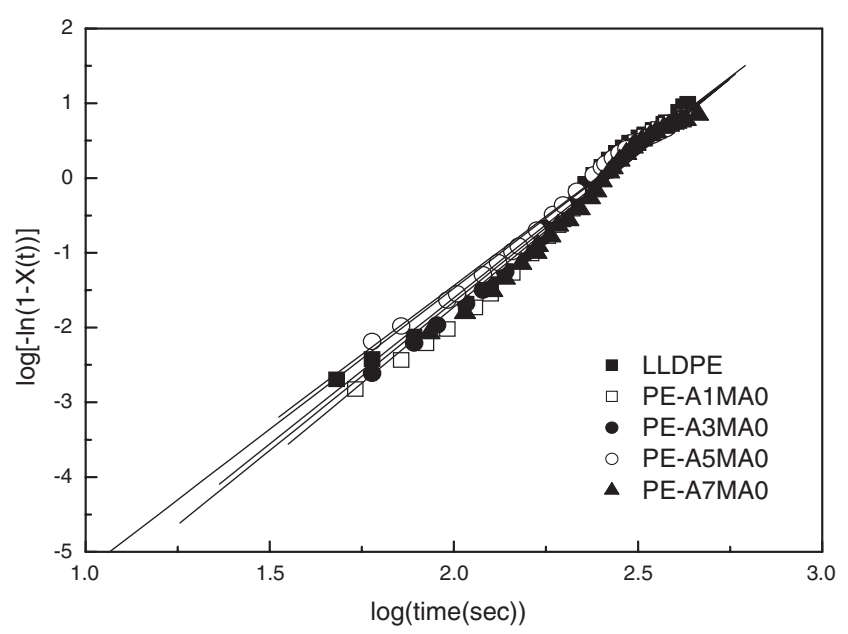

(a)

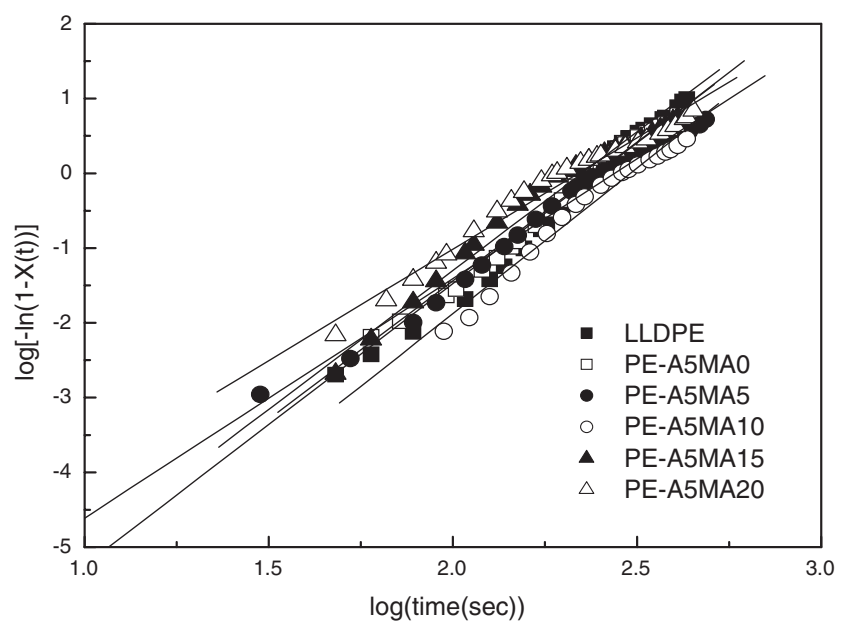

(b)

Figure 6. Plots of $\log [-\ln (1-X(t))] v s . \log t$ of LLDPE/20A composites before (a) and after (b) loading MA-g-PE. Cooling rate is $-5^{\circ} \mathrm{C} / \mathrm{min}$ and solid lines indicate linear regression.

where $T_{0}$ is the onset of the crystallization curve and $\phi$ is a cooling rate. Figures 5(a) and 5(b) show the relative crystallinity of the LLDPE/clay composites at $-1{ }^{\circ} \mathrm{C} / \mathrm{min}$. In case of the composites without MA$\mathrm{g}-\mathrm{PE}$ as shown in Figure 5(a), there is no detectable deviation in plot of relative crystallinity versus time. The fact to lie on a single correlation suggests that the crystallization behavior of LLDPE/clay composites is not significantly altered. However, there are some deviations for the composites with MA-g-PE as shown in Figure 5(b). The deviation, of course, indicates a change in crystallization behavior.

To investigate the effect of the maleated modification on the crystallization kinetics further, the plot of $\log [-\ln (1-X(t))]$ against $\log t$ was made for the LLDPE/20A composites as shown in Figure 6. According to Avrami equation, the kinetic parameters $n$ and $K$ can be obtained from the slope and intercept of the line, respectively, and the results are summarized in Table II. The composites with MA-g-PE show 


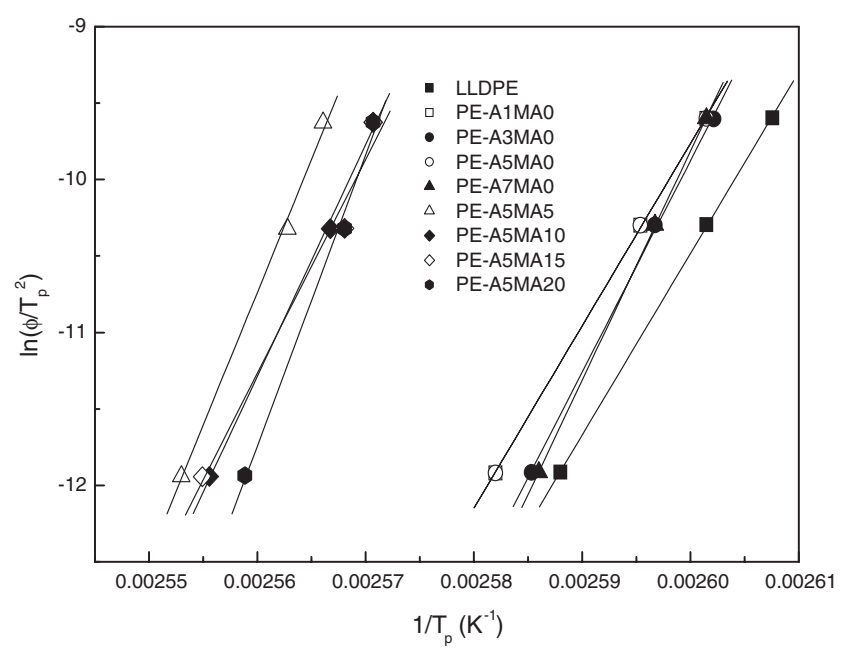

Figure 7. Plots of $\ln \left(\phi / T_{\mathrm{p}}^{2}\right)$ vs. $1 / T_{\mathrm{p}}$ for the LLDPE/20A composites. Solid lines indicate linear regression.

Table III. The activation energy and nucleation activity of LLDPE/20A composites

\begin{tabular}{lcc}
\hline \multicolumn{1}{c}{ Sample } & $\begin{array}{c}\text { Activation energy } \\
\left(\Delta E_{\mathrm{T}}\right), \mathrm{J} / \mathrm{mol}\end{array}$ & $\begin{array}{c}\text { Nucleation activity } \\
(\varepsilon)\end{array}$ \\
\hline LLDPE & 986 & - \\
PE-A1MA0 & 992 & 0.87 \\
PE-A3MA0 & 1149 & 0.82 \\
PE-A5MA0 & 949 & 0.75 \\
PE-A7MA0 & 1245 & 0.87 \\
PE-A5MA5 & 1445 & 0.37 \\
PE-A5MA10 & 1259 & 0.48 \\
PE-A5MA15 & 1160 & 0.56 \\
PE-A5MA20 & 1581 & 0.50 \\
\hline
\end{tabular}

slightly lower $n$ values than that of PE-A5MA0 but the difference is a negligible quantity.

Considering the influence of the various cooling rate on the nonisothermal crystallization process, Kissinger ${ }^{21}$ suggested a method to determine the activation energy for the transport of the macromolecular segments to the growing surface. The activation energy, $\Delta E_{\mathrm{T}}$ can be determined as follows:

$$
\frac{d\left[\ln \left(\phi / T_{\mathrm{P}}^{2}\right)\right]}{d\left(1 / T_{\mathrm{P}}\right)}=\frac{-\Delta E_{\mathrm{T}}}{R}
$$

where $T_{\mathrm{p}}$ is the peak temperature for the crystallization curve and $R$ is the gas constant. Plots of $\ln \left(\phi / T_{\mathrm{p}}^{2}\right)$ vs. $1 / T_{\mathrm{p}}$ are shown in Figure 7. Activation energies obtained from the slope of the line are $986 \mathrm{~kJ} / \mathrm{mol}$ for LLDPE, $949 \mathrm{~kJ} / \mathrm{mol}$ for PE-A5MA0, $1445 \mathrm{~kJ} / \mathrm{mol}$ for PE-A5MA5, and $1581 \mathrm{~kJ} / \mathrm{mol}$ for PE-A5MA20 as shown in Table III. These results show that $\Delta E_{\mathrm{T}}$ of the composite with MA-g-PE is larger than that of PE-A5MA0 without MA-g-PE. This may result from an increase in melt viscosity of the composite with MA-g-PE due to the confine-

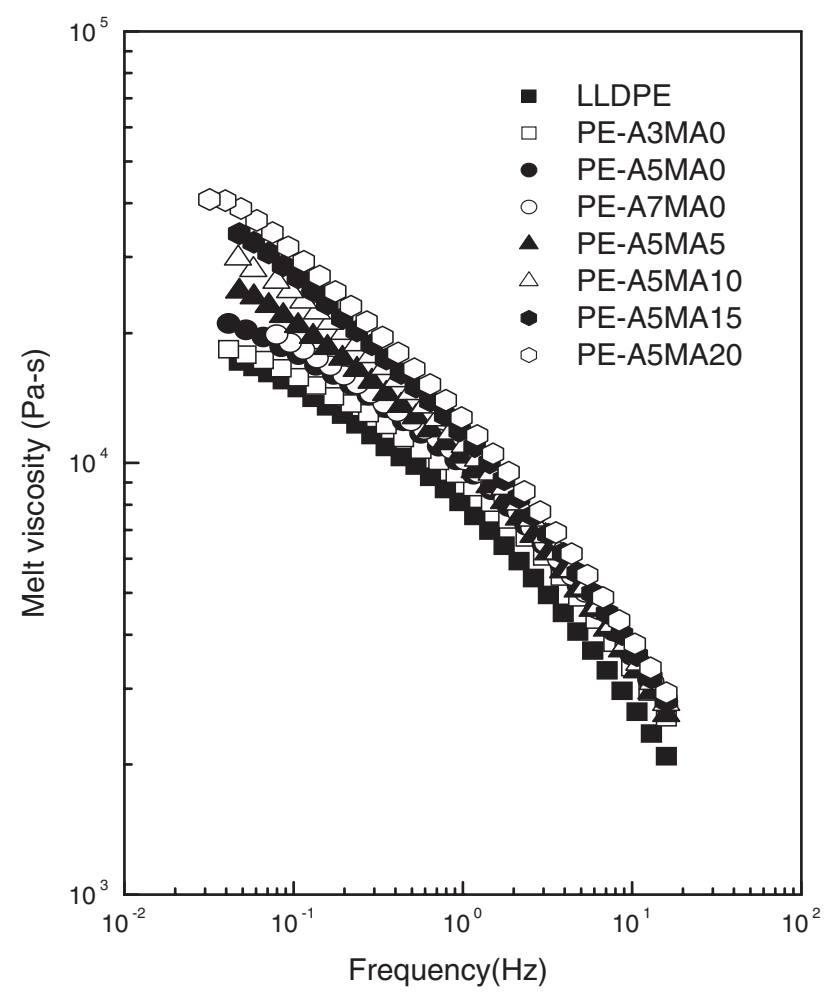

Figure 8. Melt viscosity of LLDPE/20A composites as a function of frequency.

ment effect of the clay on the motion of the polymer chains, as reported in our previous work ${ }^{18}$ and literature. $^{9,22}$ The melt viscosities obtained for LLDPE/ $20 \mathrm{~A}$ composites before and after loading MA-g-PE are shown in Figure 8. The measured temperature and strain were $200{ }^{\circ} \mathrm{C}$ and $5 \%$, respectively. All data presented in this paper was verified to be in the linear regime at $200{ }^{\circ} \mathrm{C}$ and $5 \%$ strain. The melt viscosities of the composites without MA-g-PE showed a monotonic increase at all frequency ranges with increasing $20 \mathrm{~A}$. On the other hand, there was a completely different flow pattern at low frequency region for the LLDPE/20A composites with MA-g-PE. The melt viscosity of LLDPE/20A composite containing 5 wt $\%$ clay dramatically increased with MA-g-PE concentration at the low frequency. The similar behaviors were observed for the silicate-based nanocomposites. ${ }^{18,23,24}$ The silicate layers would form network locally despite the intercalation or exfoliation of a composite due to the highly anisotropic nature of the layered silicates. The network formation of the composites results in the increase of melt viscosity.

Although the presence of the clay into LLDPE with MA-g-PE results in the increase of the activation energy, the composite exhibited also a decrease in the degree of super cooling effect, which may arise from the nucleation effect of the clay. Dobreva ${ }^{25}$ proposed a simple method to calculate the nucleating activity of the filler. According to ref 25, in the case of study 
of the nonisothermal crystallization process the following relationships were proposed:

$$
\log \phi \approx \text { const. }-\frac{B}{2.3 \Delta T_{\mathrm{P}}^{2}}
$$

where $\Delta T_{\mathrm{p}}$ is the difference between melting temperature and exothermic peak temperature, and $B$ is a parameter which can be calculated from the molar volume of the crystallizing polymer, the melting entropy, the specific surface energy and a geometrical factor. The activity of the nucleation of the filler, $\varepsilon$ is defined as the ratio between the three-dimensional work of nucleation with and without filler $\left(A_{\mathrm{f}}\right.$ and $A_{0}$, respectively). If the filler is extremely active for nucleation, $\varepsilon$ approaches zero. And for absolutely inert particles $\varepsilon$ is one. The three-dimensional work of nucleation, $A$ is equal to $n T_{\mathrm{m}} B$, where $n$ is the Avrami exponent and $T_{\mathrm{m}}$ is melting temperature. The following relationship holds:

$$
\varepsilon=\frac{A_{\mathrm{f}}}{A_{0}}=\frac{n_{\mathrm{f}} T_{\mathrm{mf}} B_{\mathrm{f}}}{n_{0} T_{\mathrm{m} 0} B_{0}}
$$

The nucleation activity $\varepsilon$ can be calculated by the slopes of the linear curves of $\log (\phi) v s . B /\left(2.3 \Delta T_{\mathrm{p}}^{2}\right)$ based on LLDPE matrix. Figure 9 shows the plots of $\log (\phi)$ against $B /\left(2.3 \Delta T_{\mathrm{p}}^{2}\right)$ for the LLDPE/20A composites. The slopes of the line are 1338 for LLDPE, 1105 for PE-A1MA0, 1062 for PE-A3MA0, 1016 for PE-A5MA0, 1107 for PE-A7MA0, 580 for PE-A5MA5, 639 for PE-A5MA10, 768 for PEA5MA15, and 842 for PE-A5MA20. The nucleation activity, $\varepsilon$ calculated by above equation are summarized in Table III. The activities of the LLDPE/20A composites without MA-g-PE are in the range of $0.72-0.83$. On the other hand, the values of the composites with MA-g-PE are in the range of 0.39-0.54.

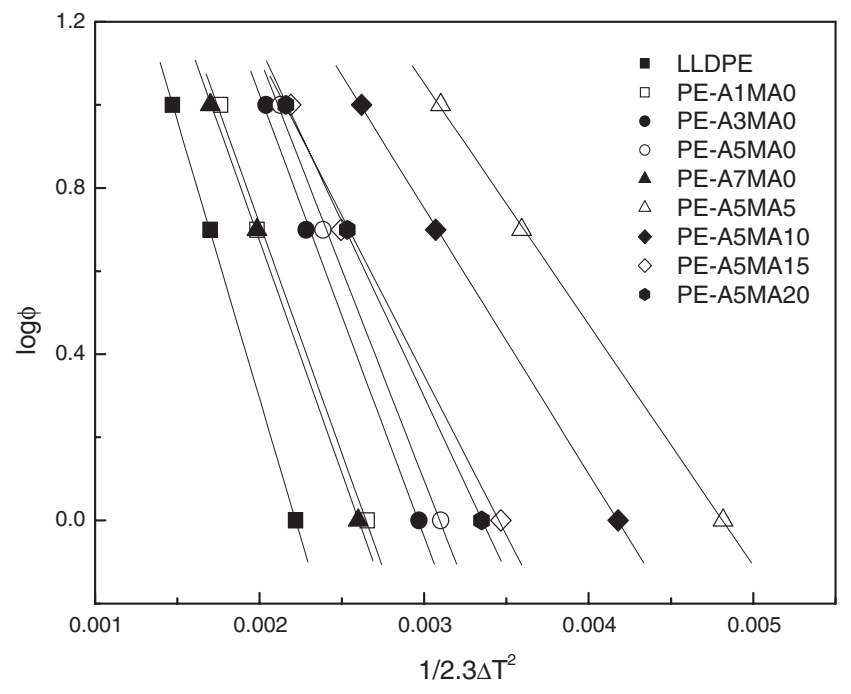

Figure 9. Plots of $\log \phi$ vs. $1 / 2.3 \Delta T_{\mathrm{p}}^{2}$ for the LLDPE/20A composites. Solid lines indicate linear regression.
This result shows that the silicate (20A) is an effective nucleating agent and the composite system with MA$\mathrm{g}-\mathrm{PE}$ is more active in nucleation process. Consequently, the results in our work indicate that the silicate dispersion in LLDPE matrix affects the degree of super cooling and nucleation activity of silicate. To clarify whether it is the effect of dispersion of clay or that of presence of MA-g-PE, the same procedure was also applied to the blend with MA-g-PE in the LLDPE resin. There was no detectable change in crystallization behavior of the pure LLDPE and LLDPE with MA-g-PE even though data are not present here.

\section{CONCLUSIONS}

The reflection peak at $2.29 \mathrm{~nm}$ disappeared when the content of MA-g-PE was higher than $15 \mathrm{wt} \%$. This fact indicates that clays are exfoliated and dispersed homogeneously in the LLDPE/20A nanocomposites as certified by TEM image. The effects of maleated modification on the crystallization behavior of LLDPE/20A nanocomposites were examined by varying MA-g-PE concentration. The LLDPE/20A composites with MA-g-PE showed an increase in the exothermic peak temperature and activation energy compared with the LLDPE/20A composites without MA-g-PE. The nucleation activity $(\varepsilon)$ of PEA5MA0 without MA-g-PE was 0.75. On the other hand, the values of the composites with MA-g-PE were in the range of $0.37-0.56$. These results show that the silicate $(20 \mathrm{~A})$ is an effective nucleating agent and the composite system with MA-g-PE is more active in nucleation process. Consequently, the results in our work indicate that the silicate dispersion in LLDPE matrix affects the degree of super cooling and nucleation activity of silicate.

\section{REFERENCES}

1. D. Kawashima, T. Aihara, Y. Kobayashi, T. Kyotani, and A. Tomita, Chem. Mater., 12, 3397 (2000).

2. H. Y. Byun, M. H. Choi, and I. J. Chung, Chem. Mater., 13, 4221 (2001).

3. K. H. Wang, I. J. Chung, M. C. Jang, J. K. Keum, and H. H. Song, Macromolecules, 35, 5529 (2002).

4. L. L. Beecroft and C. K. Ober, Chem. Mater., 9, 1302 (1997).

5. R. Gangopadhyay and A. De, Chem. Mater., 12, 608 (2000).

6. Y. Kojima, A. Usuki, M. Kawasumi, Y. Fukushima, A. Okada, T. Kurauchi, and O. Kamigaito, J. Mater. Res., 8, 1185 (1993).

7. R. Limary, S. Swinnea, and P. F. Green, Macromolecules, 33, 5227 (2000).

8. L. Zheng, R. J. Farris, and E. B. Coughlin, Macromolecules, 34, 8034 (2001).

9. J. Li, C. Zhou, and W. Gang, Polym. Test., 22, 217 (2003). 
10. C. Saujanya and S. Radhakrishnan, Polymer, 42, 6723 (2001).

11. C. M. Koo, H. T. Ham, S. O. Kim, K. H. Wang, I. J. Chung, D. C. Kim, and W. C. Zin, Macromolecules, 35, 5116 (2002).

12. S. Q. Wange and P. A. Drda, Macromolecules, 29, 2627 (1997).

13. N. Furuichi, Y. Kurokawa, K. Fujita, A. Oya, H. Yasuad, and M. Kiso, J. Mater. Sci., 31, 4307 (1996).

14. P. H. Nam, P. Maiti, M. Okamoto, T. Kotaka, N. Hasegawa, and A. Usuki, Polymer, 42, 9633 (2001).

15. Y. Kurokawa, H. Yasuda, and A. Oya, J. Mater. Sci., 35, 1045 (2000)

16. M. Kawasumi, N. Hasegawa, M. Kato, A. Usuki, and A. Okada, J. Appl. Polym. Sci., 67, 87 (1998).
17. X. Liu and Q. Wu, Polymer, 42, 10013 (2001).

18. Y. C. Kim, S. J. Lee, J. C. Kim, and H. Cho, Polym. J., 37, 206 (2005).

19. M. Sikka, L. N. Cerini, S. S. Ghosh, and K. I. Winey, J. Polym. Sci., Part B: Polym. Phys., 34, 1443 (1996).

20. C. R. Herrero and J. L. Acosta, Polym. J., 26, 786 (1994).

21. H. E. Kissinger, J. Res. Natl. Bur. Stand., 57, 217 (1956).

22. J. S. Michael, S. A. Abdulwahab, F. S. Kurt, S. Anongnat, and V. Priya, Macromolecules, 341864 (2001).

23. A. Lele, M. Mackley, G. Galgali, and C. Ramesh, J. Rheol., 46, 1091 (2002).

24. K. H. Wang, M. H. Choi, C. K. Koo, Y. S. Choi, and I. J. Chung, Polymer, 42, 9819 (2001).

25. A. Dobreva and I. Gutzow, J. Non-Cryst. Solids 162, 13 (1993). 